\title{
Rabbit Hemorrhagic Disease Virus Detected in Pico, Azores, Portugal, Revealed a Unique Endemic Strain with More Than 17 Years of Independent Evolution
}

\author{
Pedro J. Esteves ${ }^{1,2,3, *}$, Ana M. Lopes ${ }^{1,2,4}$, Maria J. Magalhães ${ }^{1}$, Ana Pinheiro ${ }^{1,2,5}$, \\ David Gonçalves ${ }^{1,2}$ and Joana Abrantes ${ }^{1}$
}

1 Centro de Investigação em Biodiversidade e Recursos Genéticos, InBIO Laboratório Associado (CIBIO), Vairão, 4485-661 Portugal; E-Mails: analopes@cibio.up.pt (A.M.L.); magalhaes.mjtr@hotmail.com (M.J.M.); ana.pinheiro@cibio.up.pt (A.P.); drgoncal@fc.up.pt (D.G.); jabrantes@cibio.up.pt (J.A.)

2 Departamento de Biologia, Faculdade de Ciências da Universidade do Porto, Porto, 4169-007, Portugal

3 Instituto de Investigação e Formação Avançada em Ciências e Tecnologias da Saúde (CESPU), Gandra, 4585-116, Portugal

4 INSERM, UMR892; CNRS, UMR629; Université de Nantes, Nantes, 44007, France

5 SaBio-IREC (CSIC-UCLM-JCCM), Ciudad Real, 13071, Spain

* Author to whom correspondence should be addressed; E-Mail: pjesteves@cibio.up.pt; Tel.: +351-252-660-411.

Received: 22 May 2014; in revised form: 23 June 2014 / Accepted: 4 July 2014 /

Published: 14 July 2014

\begin{abstract}
Rabbit hemorrhagic disease is caused by a calicivirus, rabbit hemorrhagic disease virus (RHDV), which is responsible for high mortality in domestic and wild European rabbits (Oryctolagus cuniculus). RHDV strains were sequenced from wild European rabbits (Oryctolagus cuniculus algirus) collected in the Azorean island of Pico, Portugal. Phylogenetic analyses showed that the Pico RHDV strains diverge from all of the others described so far, but cluster with the genogroups 1-5 (G1-G5). The genetic distance between the Pico RHDV sequences and each G1, G2 and G3-G5 genogroup $(\sim 0.08)$ is compatible with an RHDV introduction at least 17 years ago. Our results show that in Pico, RHDV is the outcome of an independent evolution from the original RHDV strain that appeared in its European rabbit population. These are the first sequences of RHDV obtained in the subspecies $O$. c. algirus, outside of its original region, the Iberian
\end{abstract}


Peninsula. Furthermore, we discuss the risk of rabbit translocations from the Azores to the Iberian Peninsula, where the rabbit wild populations are suffering high mortalities.

Keywords: RHDV; European rabbit; Azores; endemism

\section{Introduction}

In the Iberian Peninsula, two subspecies of European rabbit are found, O. cuniculus subsp. algirus and $O$. cuniculus subsp. cuniculus, both equally fatally susceptible to rabbit hemorrhagic disease virus (RHDV) [1]. The O. c. algirus subspecies is restricted to the southwest of the Iberian Peninsula, the Azores, Madeira and the Canary Islands. The introduction of the European rabbit in the Azores occurred in the 15th century by Portuguese navigators [2]. The genetic diversity of these populations is a subset of the genetic diversity of the Iberian Peninsula populations [3-5].

RHDV is a single-stranded, positive-sense RNA virus of the genus Lagovirus, family Caliciviridae, first detected in China in 1984, that then spread worldwide (reviewed in [1]). Genetic comparative studies showed that pathogenic and non-pathogenic RHDV strains are genetically independent, with more than $20 \%$ of divergence [6-10]. Pathogenic strains can be divided into three groups: RHDV, which include older strains of the genogroups, 1-5 (G1-G5) [11]; RHDVa (genogroup G6), characterized by a distinct antigenic profile [12]; and RHDV2, a new variant that differs from other pathogenic viral forms by more than 15\% [13-16]. In the wild European rabbit populations from the Iberian Peninsula, all RHDV strains identified before 2011 belonged to G1 [17-19]. From 2012, only RHDV2 was detected, which suggests the replacement of G1 by RHDV2 [15,20,21]. In the Azores islands, the first outbreaks of RHDV were recorded from 1988-1993 [22-24]; the first reports of RHDV in Portugal date back to 1989 [1].

\section{Materials and Methods}

In 2013, our laboratory, Centro de Investigação em Biodiversidade e Recursos Genéticos CIBIO, Universidade do Porto, Portugal, received five rabbit liver samples, belonging to O. cuniculus subsp. algirus, collected in the Portuguese Azorean island of Pico. The rabbits appeared dead in the field and had gross (pathological) lesions compatible with rabbit hemorrhagic disease (RHD). Total RNA of the samples was extracted with the RNeasy Mini Kit (QIAGEN, Hilden, Germany), according to the manufacturer's instructions. Reverse transcription (RT) was performed by using oligo(dT) as the primer (Invitrogen, Carlsbad, CA, USA) and SuperScript III reverse transcription (Invitrogen), as recommended by the manufacturer. Screening of the samples employed several RT-PCR assays designed to result in overlapping amplification products covering the entire VP60 gene (the PCR conditions are available on request). After purification, PCR products were sequenced on an automatic sequencer ABI PRISM 310 Genetic Analyzer (PE Applied Biosystems, Foster City, CA, USA) with the pairs of primers used for amplification.

All five samples were PCR-positive for RHDV. The obtained sequences were aligned with sequences available from public databases. Withdrawn sequences represent the RHDV groups G1-G5, 
RHDVa, RHDV2 and the nonpathogenic groups. Since the occurrence of recombination in the RHDV strains has been reported [25,26], we screened the alignment for recombination using RDP v4.35 [27]. The phylogenetic tree was inferred in MEGA6 [28] by using a maximum-likelihood (ML) approach. The reliability of the nodes was assessed with a bootstrap resampling procedure consisting of 500 replicates of the ML trees. The best-fit nucleotide substitution model was determined by using MEGA6. Pairwise genetic distances and between group means distances were calculated in MEGA6 [28].

\section{Results}

In the RHDV sequences recovered from Pico, a total of seven nucleotide changes were observed, two of which were non-synonymous. Genetic distances calculated using the pairwise distance between each of these sequences varied between $0.01 \%$ and $0.03 \%$. The inferred ML phylogenetic tree is in agreement with those published (Figure 1) [14-16]. Indeed, the pathogenic strains appear in two very well-supported main groups: (1) RHDV strains (G1-G5) and RHDVa; and (2) the new variant, RHDV2. The Pico RHDV sequences (Pico-13) form a highly supported group (bootstrap value: 100), and although more closely related with the RHDV strains (G1-G5), they differ from each RHDV group (G1, G2 and G3-G5) by approximately 8\% (between group means distances). No evidence of recombination was found. The amino acid differences obtained between Pico samples and the other pathogenic RHDV strains are shown in Figure 2. Six distinct regions (A to F) can be distinguished in the RHDV VP60 capsid. The $\mathrm{C}$ and $\mathrm{E}$ regions are located in the exposed P2 subdomain and show the highest degree of genetic variation [29]. The non-synonymous substitutions observed in Pico strains are localized in the region, $\mathrm{C}$, amino acid 307, and F, amino acid 477 (Figure 2). Interestingly, positive selection for the amino acid position 307 has been reported; the position 477 is adjacent to residue 476, which has also been identified as evolving under positive selection [30]. 
Figure 1. Maximum-likelihood phylogenetic tree of 74 complete capsid gene sequences of rabbit hemorrhagic disease virus (RHDV). Bootstrap values appear next to the nodes and are shown only for the major groups: RHDV Genogroup 1 (G1) (GenBank Accession Nos. JX886002, JF438967, JX886001, EF558578, Y15440, Z24757, L48547, Z49271, Z29514); RHDV G2 (GenBank Accession Nos. KF494932, KF494947, AF231353, KF494924, KF494921, U54983, EF558580, EF558579, M67473, EU003579, JN851735, EU650679, GU373618, AF402614, AF295785, FR823355, U49726, EU003580, FJ212323); RHDV G3-5 (GenBank Accession Nos. FR823354, AJ535092, EF558585, Y15441, EF558575, EF558577, Y15426, X87607, AJ535094, EF558574, Y15424, EF558573, EF558572); RHDV2 (GenBank Accession Nos. HE800529, HE800530, HE800531, HE800532, HE819400, FR819781, JQ929052, JX106023, KC345611，KC345612， KC345613); RHDVa (GenBank Accession Nos. EU003582, EF558583, EF558584, AB300693, EU003581, DQ205345, EF558582, AF258618, JF412629, HM623309, AY523410, EU003578, EF558581, DQ280493). European brown hare syndrome virus (EBHSV) was used to root the tree (GenBank Accession No. NC_002615). The non-pathogenic strain from Australia (GenBank Accession No. EU871528) and the moderate pathogenic strain from the United States of America (GenBank Accession No. GQ166866) were also included. The samples isolated from the rabbits found in Pico, Portugal, appear in bold (Pico13-05, Pico13-12, Pico13-26, Pico13-31, Pico13-32, GenBank Accession Nos. KJ579156-KJ579160). The scale bar indicates the nucleotide substitutions per site.

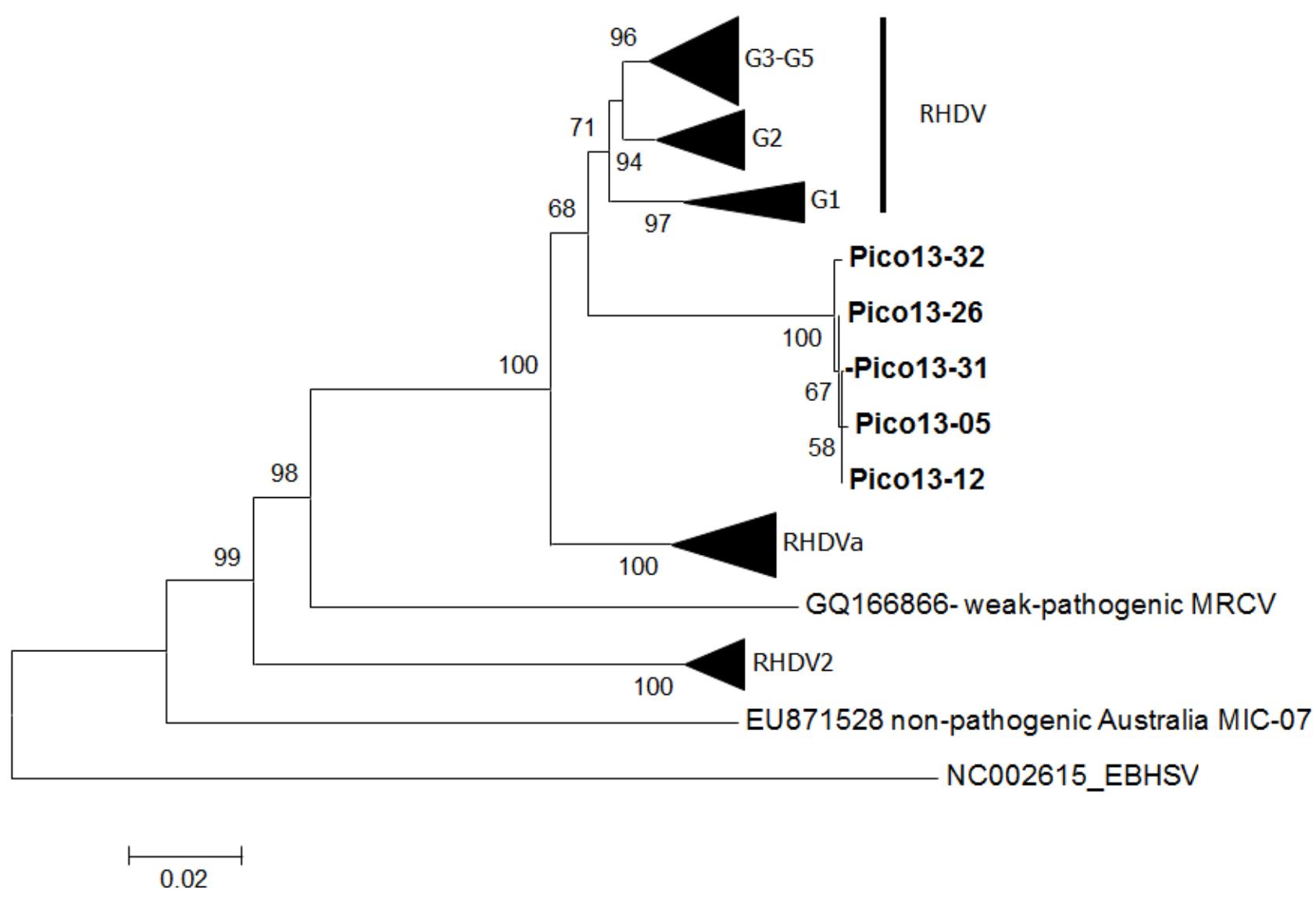


Figure 2. Amino acid polymorphic positions in the RHDV VP60 capsid. The different capsid regions are indicated at the top [29]. Dots represent the identity with the sequence Pico13-05 (GenBank Accession number KJ579156).

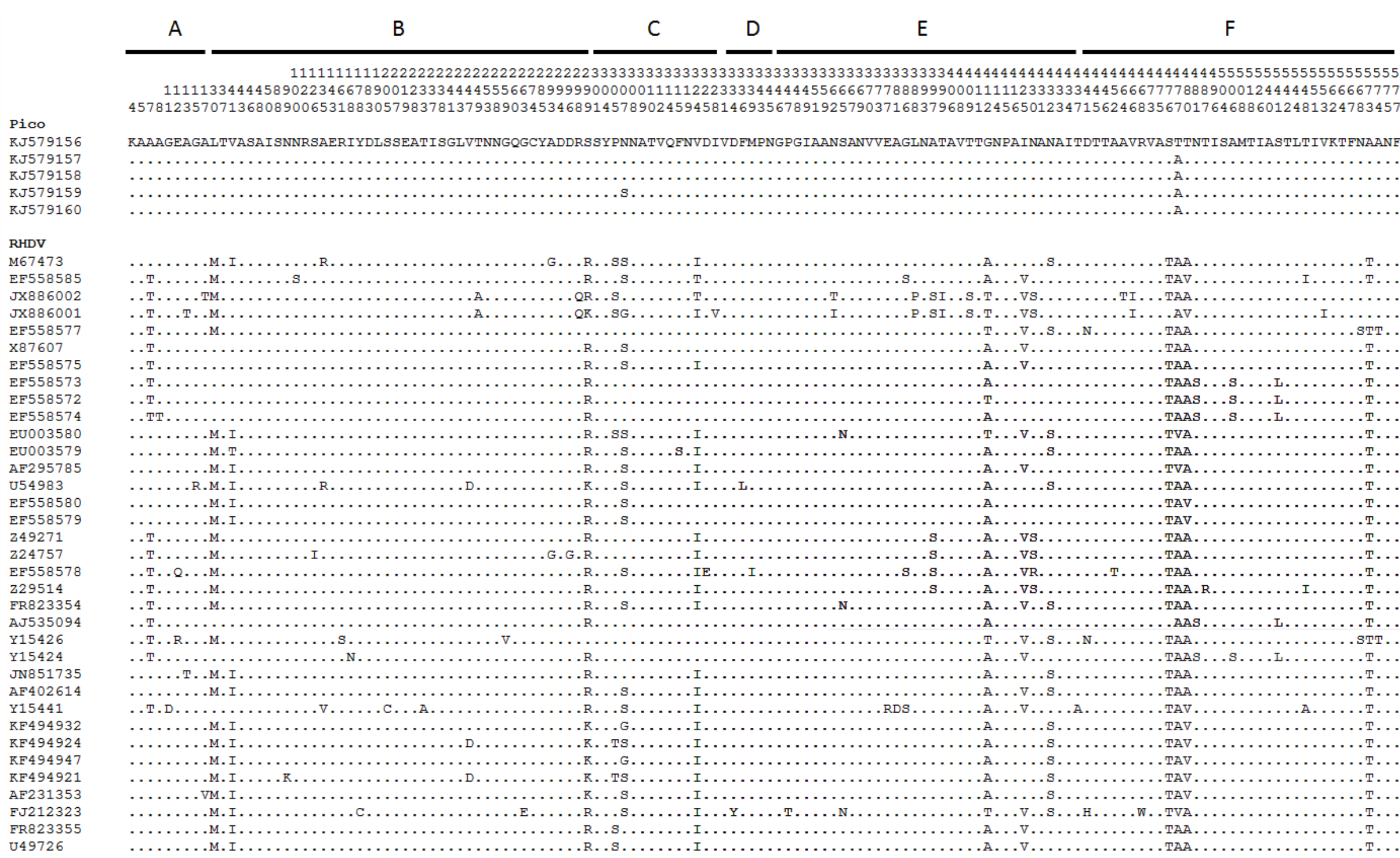


Figure 2. Cont.

111111111122222222222222222222222333333333333333333333333333333333333333444444444444444444444444444444555555555555555555555 1111133444458902234667890012333444455566789999900000011111222333344444455666677788899900011111233333344456667777888900012444445566667777
45781235707136808900653188305798378137938903453468914578902459458146935678919257903716837968912456501234715624683567017646886012481324783457

RHDV

AJ535092

EU650679

L 48547

Y15440

JF438967

GU373618

RHDVa

RF558583

EF5 0035832

EF5 558584

DQ205345

EF558582

AY523410

EF558581

HM623309

AB300693

EU003581

EU003578

DQ280493

JF412629

RHDV2

HE 800529

FR819781

HE 800532

HE 800531

HE 800530

HE819400

JQ929052

RC345613

JX106023

RC345612

KC 345611

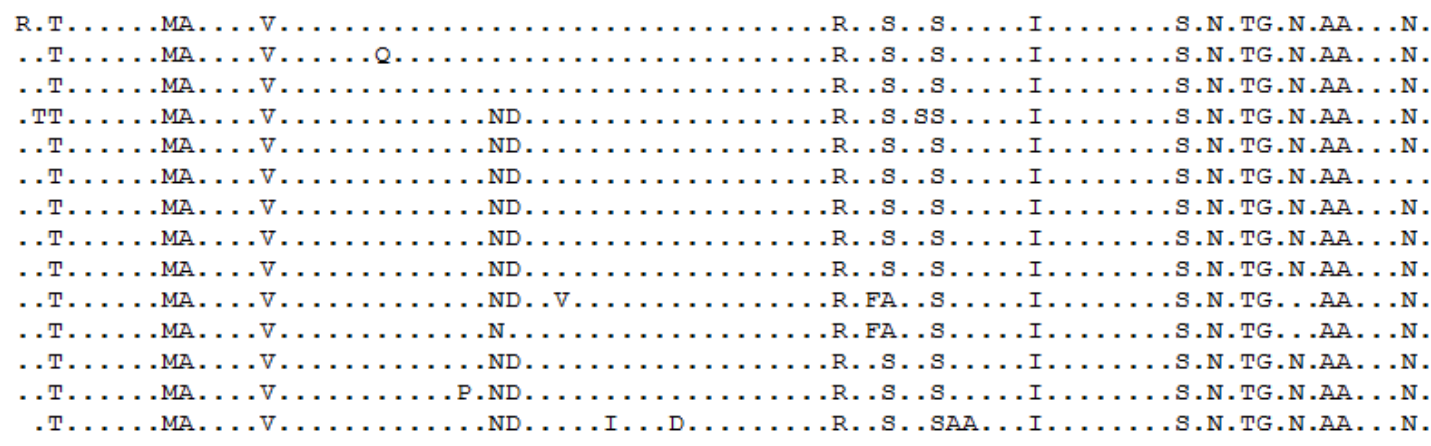

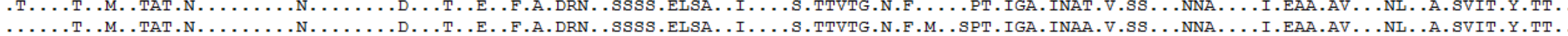

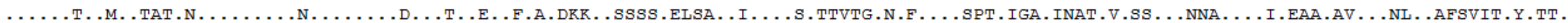

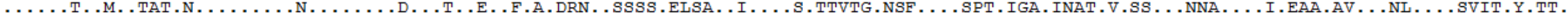

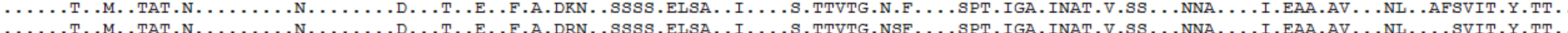

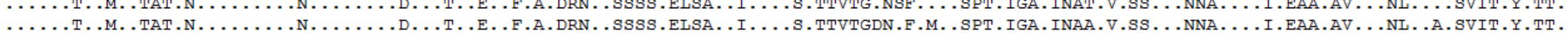

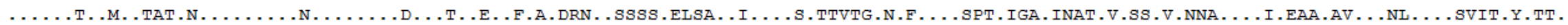

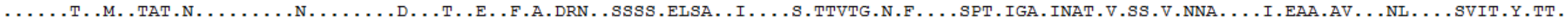

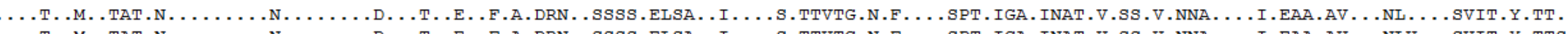

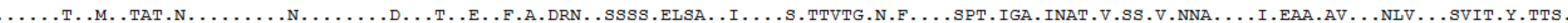




\section{Discussion}

In the Iberian Peninsula, RHDV was first detected in 1988 in Spain and in 1989 in Portugal [1]. Later, phylogenetic studies revealed an independent isolated evolution of the virus with the detection of only G1 strains [17-19]. In 2011, the new variant RHDV, described in 2010 in France [13], was reported in Spain [14] and seems to be replacing G1-G5 strains [13,15,16,20,21]. In the Azores, the earliest reports of RHD date back to 1988 in Faial, which is located $9 \mathrm{~km}$ from Pico [24]. However, this and other reports of the disease are not conclusive, as the descriptions are minimal. In 2005, the presence of RHDV in Pico was confirmed by the Portuguese Reference Laboratory, but no genetic data were reported.

Despite the patchy information on the history of RHDV in the Azores, our results suggest that the RHDV strains recovered in Pico have evolved independently since the arrival of the virus on this island, becoming a variant of RHDV clearly distinct from all of the other RHDV groups described so far. Nevertheless, the unavailability of samples from previous years prevents us from conducting a phylodynamic analysis that could help to fully determine the origin and relationship of the recovered strains with those that originated other outbreaks in Pico.

A pattern similar to the one observed in Pico was recently observed in Australia, with several RHDV strain lineages having emerged from the originally introduced Czech strain [31]. Indeed, in Australia, the RHDV mutation rate was estimated at $4.0 \times 10^{-3}$ nucleotide substitutions/per nucleotide/per year (with an interval between 3.3-4.7 $\times 10^{-3}$ ). Comparing the Pico sequences with the first G1 and G2 reported in the early 1990s or G3-G5 from 1994 allowed us to estimate a genetic distance of $\sim 0.08$; given the mutation rates observed for RHDV in Australia, this would imply a divergence time (or a time to most recent common ancestor) of 20 years with a variance between 24 and 17 years. This scenario is compatible with the appearance of RHDV in Pico between 1989 and 1996, followed by an independent evolution. This would mean that all three main groups (G1, G2 and G3-G5) could have been at the genesis of the RHDV strains detected in Pico. Therefore, the emergence of RHDV in the Azores Islands, an archipelago in the Atlantic Ocean, $1500 \mathrm{~km}$ from Europe and Africa, could have occurred by several pathways (birds, trade, tourism) with different origins.

The results show the presence of an RHDV strain in wild rabbits of Pico, Azores, with unique characteristics. Unfortunately, epidemiological information is not available; information on the outbreaks, the mortality in the population and the immune status of the population is scarce. Considering the genetic distance between RHDV Pico and the G1-G5, the former is probably an antigenic subtype of the later, and this means that rabbits infected with G1-G5 have a high probability of being almost fully protected from RHD caused by Pico RHDV. However, the G1-G5 strains seem to have been replaced by RHDV2, both in the wild populations and the domestic breeds $[15,16,19,20]$. This means that probably in the next few years, European rabbit populations will lose their protection against the G1-G5 RHDV strains.

The O. cuniculus algirus only occurs in the southwestern part of the Iberian Peninsula and is a key prey species for several carnivores, including the most endangered feline, the Iberian lynx (Lynx pardinus). O. c. algirus populations from the mainland are suffering a severe decline due to RHDV [15,20]. Thus, translocations from island populations could be thought of as a solution. Translocations of rabbits from the Azores area to the Iberian mainland should be considered only after 
a careful study of the main characteristics of this new subtype in order to avoid making worse the already critical condition of the $O$. c. algirus populations, pushing it towards its extinction instead of its recovery. Furthermore, these results show that islands are good models to study viral evolution.

\section{Acknowledgments}

The samples from Pico were provided by the Direção Regional dos Recursos Florestais (DDRF), namely through Serviço Florestal do Pico (SFP); our thanks to Manuel Leitão (DRRF) and José Costa (SFP); also to Manuel Humberto, a local hunter.

The Portuguese Foundation for Science and Technology supported the doctoral fellowship of Ana M. Lopes (ref.: SFRH/BD/78738/2011) and Ana Pinheiro (ref.: SFRH/BD/71252/2010) and the FCT Investigator grant of Joana Abrantes (ref.: IF/01396/2013). This work is funded by OE Funds - State budget through the FCT - Foundation for Science and Technology under the project FCT-ANR/BIABIC/0043/2012. Furthermore, the project "Genomics Applied to Genetic Resources", co-financed by the North Portugal Regional Operational Programme 2007/2013 (ON.2-O Novo Norte), under the National Strategic Reference Framework, through the European Regional Development Fund, supported this work.

\section{Author Contributions}

Pedro J. Esteves conceived of this study, analyzed the data and wrote the draft manuscript. Ana M. Lopes and Maria J. Magalhães carried out the molecular genetics analysis. Ana Pinheiro and Joana Abrantes discussed the data and participated in the writing of the manuscript. David Gonçalves participated in the sampling and discussed the data.

\section{Conflicts of Interest}

The authors declare no conflict of interest.

\section{References and Notes}

1. Abrantes, J.; van der Loo, W.; le Pendu, J.; Esteves, P.J. Rabbit haemorrhagic disease (RHD) and rabbit haemorrhagic disease virus (RHDV): A review. Vet. Res. 2012, 43, 12. doi:10.1186/1297-9716-43-12.

2. Correa, A.J. História do descobrimento das Ilhas dos açores e sua denominação de Ilhas Flamengas. In Revista Michaelense; S. Miguel: Açores, Portugal, 1918.

3. Van der Loo, W.; Mougel, F.; Sánchez, M.S.; Bouton, C.; Castien, E.; Fonseca, A.; Ferrand, N.; Soriguer, R.; Monnerot, M. Cytonuclear disequilibria in wild populations of rabbit (Oryctolagus cuniculus L.) suggest unequal allele turnover rates at the b locus (IGKC1). Immunogenetics 1999, 49, 629-643.

4. Esteves, P.J.; Lanning, D.; Zhai, S.-K.; Ferrand, N.; Knight, K.L.; van der Loo, W. Allelic variation at the VHa locus in natural populations of rabbit (Oryctolagus cuniculus, L.). J. Immunol. 2004, 172, 1044-1053. 
5. Ferrand, N. Inferring the evolutionary history of the European rabbit (Oryctolagus cuniculus) from molecular markers. In Lagomorph Biology: Evolution, Ecology, and Conservation, 1st ed.; Alves, P.C., Ferrand, N., Hackländer, K., Eds.; Springer: Berlin, Germany, 2008; pp. 47-63.

6. Capucci, L.; Fusi, P.; Lavazza, A.; Pacciarini, M.L.; Rossi, C. Detection and preliminary characterization of a new rabbit calicivirus related to rabbit hemorrhagic disease virus but nonpathogenic. J. Virol. 1996, 70, 8614-8623.

7. Strive, T.; Wright, J.D.; Robinson, A.J. Identification and partial characterisation of a new Lagovirus in Australian wild rabbits. Virology 2009, 384, 97-105.

8. Bergin, I.L.; Wise, A.G.; Bolin, S.R.; Mullaney, T.P.; Kiupel, M.; Maes, R.K. Novel calicivirus identified in rabbits, Michigan, USA. Emerg. Infect. Dis. 2009, 15, 1955-1962.

9. Abrantes, J.; Esteves, P.J. Not-so-novel michigan rabbit calicivirus. Emerg. Infect. Dis. 2010, 8, 1331-1332.

10. Le Gall-Reculé, G.; Zwingelstein, F.; Fages, M.P.; Bertagnoli, S.; Gelfi, J.; Aubineau, J.; Roobrouck, A.; Botti, G.; Lavazza, A.; Marchandeau, S. Characterisation of a non-pathogenic and non-protective infectious rabbit lagovirus related to RHDV. Virology 2011, 410, 395-402.

11. Le Gall-Reculé, G.; Zwingelstein, F.; Laurent, S.; de Boisséson, C.; Portejoie, Y.; Rasschaert, D. Phylogenetic analysis of rabbit haemorrhagic disease virus in France between 1993 and 2000, and the characterisation of RHDV antigenic variants. Arch. Virol. 2003, 148, 65-81.

12. Capucci, L.; Fallacara, F.; Grazioli, S.; Lavazza, A.; Pacciarini, M.L.; Brocchi, E. A further step in the evolution of rabbit hemorrhagic disease virus: The appearance of the first consistent antigenic variant. Virus Res. 1998, 58, 115-126.

13. Le Gall-Reculé, G.; Zwingelstein, F.; Boucher, S.; le Normand, B.; Plassiart, G.; Portejoie, Y.; Decors, A.; Bertagnoli, S.; Guérin, J.L.; Marchandeau, S. Detection of a new variant of rabbit haemorrhagic disease virus in France. Vet. Rec. 2011, 168, 137-138.

14. Dalton, K.P.; Nicieza, I.; Balseiro, A.; Muguerza, M.A.; Rosell, J.M.; Casais, R.; Álvarez, Á.L.; Parra, F. Variant rabbit hemorrhagic disease virus in young rabbits, Spain. Emerg. Infect. Dis. 2012, 18, 2009-2012.

15. Abrantes, J.; Lopes, A.M.; Dalton, K.P.; Melo, P.; Correia, J.J.; Ramada, M.; Alves, P.C.; Parra, F.; Esteves, P.J. New variant of rabbit hemorrhagic disease virus, Portugal, 2012-2013. Emerg. Infect. Dis. 2013, 19, 1900-1902.

16. Le Gall-Reculé, G.; Lavazza, A.; Marchandeau, S.; Bertagnoli, S.; Zwingelstein, F.; Cavadini, P.; Martinelli, N.; Lombardi, G.; Guérin, J.L.; Lemaitre, E.; et al. Emergence of a new lagovirus related to Rabbit Haemorrhagic Disease Virus. Vet. Res. 2013, 44, 81. doi:10.1186/1297-9716-44-81.

17. Muller, A.; Freitas, J.; Silva, E.; le Gall-Reculé, G.; Zwingelstein, F.; Abrantes, J.; Esteves, P.J.; Alves, P.C.; van der Loo, W.; Kolodziejek, J.; et al. Evolution of rabbit haemorrhagic disease virus (RHDV) in the European rabbit (Oryctolagus cuniculus) from the Iberian Peninsula. Vet. Microbiol. 2009, 135, 368-373.

18. Alda, F.; Gaitero, T.; Suárez, M.; Merchán, T.; Rocha, G.; Doadrio, I. Evolutionary history and molecular epidemiology of rabbit haemorrhagic disease virus in the Iberian Peninsula and Western Europe. BMC Evol. Biol. 2010, 10, 347.

19. Abrantes, J.; Lopes, A.M.; Esteves, P.J. Complete genomic sequences of rabbit hemorrhagic disease virus G1 strains isolated in the European rabbit original range. J. Virol. 2012, 86, 13886. 
20. Dalton, K.P.; Nicieza, I.; Abrantes, J.; Esteves, P.J.; Parra, F. Spread of new variant RHDV in domestic rabbits on the Iberian Peninsula. Vet. Microbiol. 2014, 169, 67-73.

21. Calvete, C.; Sarto, P.; Calvo, A.J.; Maonroy, F.; Calvo, J.H. Could the new rabbit haemorrhagic disease virus variant (RHDVb) be fully replacing classical RHD strains in the Iberian Peninsula? World Rabbit Sci. 2014, 22, 91.

22. Carvalho, G. Contribuição para o estudo duma população de coelhos selvagens Oryctolagus cuniculuss na ilha de Sta Maria e o impacto do RVHD na população local; Relatórios e comunicaçãoes do Departamento de Biologia, Universidade dos Açores: Ponta Delgada, Portugal, 1992; Volume 19, pp. 61-67.

23. Carvalho, G.; Ferrand, N.; Fonseca, A.; Branco, M.; Azevedo, M.; Mendes, R.; Batista, P.; Mântua, P. Estudo de uma população de coelhos selvagens, Oryctolagus cuniculus, (L.), na ilha de S. Jorge-Açores; Relatórios e comunicaçãoes do Departamento de Biologia, Universidade dos Açores: Ponta Delgada, Portugal, 1994; Volume 21, pp. 8-20.

24. Carvalho, G.; Fonseca, A.; Cruz, A.; Célio, P.; Mantua, P.; Simões, C.; Silva, S.; Arruda, G. Estudo preliminar de alguns parâmetros de uma população de coelho selvagem (Oryctolagus cuniculus) da ilha do Faial-Açores; Relatórios e comunicaçãoes do Departamento de Biologia, Universidade dos Açores: Ponta Delgada, Portugal, 1994; Volume 22, pp. 49-60.

25. Abrantes, J.; Esteves, P.J.; van der Loo, W. Evidence for recombination in the major capsid gene VP60 of the rabbit haemorrhagic disease virus (RHDV). Arch. Virol. 2008, 153, 329-335.

26. Forrester, N.L.; Moss, S.R.; Turner, S.L.; Schirrmeier, H.; Gould, E.A. Recombination in Rabbit haemorrhagic disease virus; possible impact on evolution and epidemiology. Virology 2008, 376, 390-399.

27. Martin, D.P.; Lemey, P.; Lott, M.; Moulton, V.; Posada, D.; Lefeuvre, P. RDP3: A flexible and fast computer program for analyzing recombination. Bioinformatics 2010, 26, 2462-2463.

28. Tamura, K.; Stecher, G.; Peterson, D.; Filipski, A.; Kumar, S. MEGA6: Molecular Evolutionary Genetics Analysis version 6.0. Mol. Biol. Evol. 2013, 30, 2725-2729.

29. Neill, J.D. Nucleotide sequence of the capsid protein gene of two serotypes of San Miguel sea lion virus: Identification of conserved and non-conserved amino acid sequences among calicivirus capsid proteins. Virus Res. 1992, 24, 211-222.

30. Esteves, P.J.; Abrantes, J.; Carneiro, M.; Muller, A.; Thompson, G.; van der Loo, W. Detection of positive selection in the major capsid protein VP60 of the rabbit haemorrhagic disease virus (RHDV). Virus Res. 2008, 137, 253-256.

31. Kovaliski, J.; Sinclair, R.; Mutze, G.; Peacock, D.; Strive, T.; Abrantes, J.; Esteves, P.J.; Holmes. E.C. Molecular epidemiology of Rabbit Haemorrhagic Disease Virus in Australia: When one became many. Mol. Ecol. 2013, doi:10.1111/mec.12596.

(C) 2014 by the authors; licensee MDPI, Basel, Switzerland. This article is an open access article distributed under the terms and conditions of the Creative Commons Attribution license (http://creativecommons.org/licenses/by/3.0/). 